\begin{tabular}{|c|c|}
\hline Title & $\begin{array}{l}\text { Distribution of the Steller sea lion Eumetopias jubatus during winter in the northern Sea of Japan, al ong the west coast } \\
\text { of Hokkaido, based on aerial and land sighting surveys }\end{array}$ \\
\hline Author(s) & Hoshino, Hiroshi; Isono, Takeomi; Takay ama, Takuma; Ishinazaka, Tsuyoshi; Wada, A kihiko; Sakurai, Y asunori \\
\hline Citation & $\begin{array}{l}\text { Fisheries Science, 72(5), 922-931 } \\
\text { https://doi.org/10.1111j.1444.2906.2006.01239.x }\end{array}$ \\
\hline Issue Date & $2006-10$ \\
\hline Doc URL & http:/hdl .handle.net/2115/35585 \\
\hline Rights & ○ 2006 公益社団法人日本水産学会; @ 2006 The Japanese Society of Fisheries Science \\
\hline Type & article \\
\hline File Information & 2006-72_p922-931.pdf \\
\hline
\end{tabular}

Instructions for use 


\title{
Distribution of the Steller sea lion Eumetopias jubatus during winter in the northern Sea of Japan, along the west coast of Hokkaido, based on aerial and land sighting surveys
}

\author{
Hiroshi HOSHINO, ${ }^{\text {la }}$ TAKEOMI ISONO, ${ }^{2}$ TAKUMA TAKAYAMA, ${ }^{1}$ TsUYOSHI ISHINAZAKA, ${ }^{3 b}$ \\ AKIHIKO WADA ${ }^{4}$ AND YASUNORI SAKURAI ${ }^{*}$ \\ ${ }^{1}$ Division of Marine Environment and Resources, Graduate School of Fisheries Sciences, Hokkaido University, \\ Hakodate, Hokkaido 041-8611, ${ }^{2}$ Econixe, Shimonopporo Technopark, Sapporo, Hokkaido 004-0015, \\ ${ }^{3}$ Laboratory of Theriogenology, College of Bioresource Sciences, Nihon University, Fujisawa, Kanagawa \\ 252-8510, and ${ }^{4}$ Hokkaido Wakkanai Fisheries Experimental Station, Wakkanai, Hokkaido 097-0001, Japan
}

\begin{abstract}
Aerial and land-based sighting surveys were conducted to clarify the distribution of Steller sea lions during winter in the northern Sea of Japan, along the west coast of Hokkaido, from 2001 to 2003. Aerial surveys revealed that sea lions gathered around the Rishiri-Rebun Islands in March 2002 and 2003, and between Iwanai and Cape Obana in February 2003. Higher numbers of sea lions were also confirmed at Cape Ofuyu and Cape Kamui on the central-west coast compared to that at the haul-out sites in the 1980s on the upper-west coast in March 2002 and 2003. Additionally, fisherman observed sea lions along the coast of the Tsugaru Strait from February to May 2003, where the presence of sea lions was not reported in the 1980s. These facts suggest that sea lions have recently expanded their distribution southward. Land-based surveys at the recent haul-out sites indicated that sea lions in the central-west coast were composed mainly of adult and subadult males (average: Cape Ofuyu 75.2\%, Cape Kamui 69.5\%), which stayed from November 2002 to May 2003. In this area, sea lions arrived earlier and stayed longer than in the 1980s.
\end{abstract}

KEY WORDS: Cape Kamui, Cape Ofuyu, distribution, Eumetopias jubatus, haul-out sites, Japan Sea coast off Hokkaido, Steller sea lion.

\section{INTRODUCTION}

Steller sea lions Eumetopias jubatus are the biggest otariidae and live in the North Pacific rim from California, USA to Hokkaido, Japan. ${ }^{1}$ In the western range of the North Pacific rim, sea lions breed on Iony and Tuleny Islands near Sakhalin Island and on the Kuril Islands during summer. They then migrate to the northern Sea of Japan and Pacific Ocean along the west and east coasts of Hokkaido, respectively, in order to forage during winter. ${ }^{2}$

${ }^{*}$ Corresponding author: Tel: 81-138-40-8861.

Fax: 81-138-40-8861. Email: sakurai@fish.hokudai.ac.jp

aPresent address: Division of Innovative Research, Creative Research Initiative 'Sousei', Hokkaido University, Sapporo, Hokkaido 001-0021, Japan.

bresent address: Rausu Ranger Office, Shiretoko National Park, Ministry of the Environment, Rausu, Hokkaido 086-1822, Japan.

Received 22 October 2004. Accepted 7 May 2006.
Steller sea lions are reported to have decreased in the Sea of Okhotsk, including the Kuril Islands, since the 1960s. ${ }^{3}$ The numbers of haul-out sites (specific rocks or capes which sea lions rest on) are also reported to have decreased in Hokkaido between the 1920s and 1980s. ${ }^{4}$ In addition, catches and sightings of wintering sea lions has decreased in the Pacific Ocean along the east coast of Hokkaido during the past 30 years. ${ }^{5,6}$ However, sightings of wintering sea lions by fishermen have increased in the northern Sea of Japan, along the west coast of Hokkaido, since the early 1990s. ${ }^{7}$ This suggests that sea-lion distribution may have concentrated in the northern Sea of Japan, along the west coast of Hokkaido, in winter since the early 1990s.

Steller sea lions are optimistic feeders, and their main diet is reported to consist of Pacific cod Gadus macrocephalis, walleye pollock Theragra chalcogramma and octopus in the northern Sea of Japan, along the west coast of Hokkaido. ${ }^{8}$ These 
species are also the main targets of coastal fisheries in this area. As a result of this competition, sea lions have had a serious impact on the fishing industry (destruction of fishing gear and decreased catches of fish) in the northern Sea of Japan, along the west coast of Hokkaido, since the early 1990s. ${ }^{5,7}$ The competition of sea lions with coastal fisheries in the northern Sea of Japan, along the west coast of Hokkaido, should therefore be carefully assessed, however, the distribution of sea lions has not been studied in this area since the 1980s. In order to clarify the areas and season of competitions between sea lions and coastal fisheries, determination of current distribution of sea lions is essential.

Sea lions forage in waters and rest on haul-out sites. These haul-out sites are thought to represent a center of the sea lions distribution because sea lions are reported to use haul-out sites adjacent to their foraging areas. ${ }^{9,10}$ Also, monthly changes in sea lion numbers at specific haul-out sites are thought to reflect temporal changes in sea lion distributions in the water around the respective haulout sites. Therefore, the investigations of sea lions, both in the water and at haul-out sites, are necessary to clarify the recent distribution of sea lions.

Sex and age class of sea lions should also be investigated as the distributions of pinnipeds are different in each sex and age class (e.g. adult males, juveniles, adult females)..$^{11,12}$ Sexual segregation of wintering sea lions around Hokkaido was reported in the 1980s; the group of sea lions wintering in the northern Sea of Japan, along the west coast of Hokkaido, was composed mainly of males and the group of sea lions wintering in the Pacific Ocean along the east coast of Hokkaido was composed mainly of females. ${ }^{4}$

The aim of the present study was to determine the current distribution of sea lions in the northern Sea of Japan, along the west coast of Hokkaido. Distributions of sea lions in coastal waters and among haul-out sites in the northern Sea of Japan, along the west coast of Hokkaido, were first examined. Monthly changes in the numbers of sea lions in each sex and age class at the recent major haul-out sites were then investigated. The results were then compared with earlier reports from the 1980s.

\section{METHODS}

\section{Aerial survey and interview}

To clarify the distribution of sea lions in the northern Sea of Japan, along the west coast of Hokkaido, aerial sighting surveys and interviews were conducted in the winters of 2001-2003.
Aerial sighting surveys were conducted on: 27 January, 1 and 2 March 2001; 3 and 28 February, and 1 March 2002; 2 and 8 February, and 2 and 6 March 2003. The flights on 1 and 2 March 2001; 28 February and 1 March 2002; and 2 and 6 March 2003 were, respectively, assumed as a set of flights which covered the entire study area. Survey strips (a belt-like areas for searching sea lions) were set along the coast line between 0.5 and $2.0 \mathrm{~km}$ from the shoreline, connecting haul-out sites that have been used since the 1980s (Fig. 1). This approach was chosen as sea lions are reported to rest in the costal areas during the daytime. ${ }^{6,8}$ Survey strips were established between Okushiri Island and the Rishiri-Rebun Islands in 2001, and between the Tsugaru Strait and the Rishiri-Rebun Islands in 2002 and 2003 (Fig. 1). All flights were started from Okadama airport (see Fig. 1). A total of $1039.6 \mathrm{~km}$ was searched over 3 days in 2002, and a total of approximately $1301.6 \mathrm{~km}$ was searched over 4 days in 2003. Survey strips were searched over 3 days in 2001 , although the exact length is unknown as the global positioning system in the airplane at that time was an older model which was unable to record such information. Flights were only conducted when both of the following conditions were satisfied: (i) visibility was greater than $5 \mathrm{~km}$; and (ii) any clouds below the altitude of $300 \mathrm{~m}$ did not cover more than $62 \%$ of the sky. A flight was also stopped when either snow or cloud was observed at the flight route altitude during a flight.

Four researchers (one working as a photographer and an observer, two observers and one recording with video) and two pilots flew on a Cessna 206 single-propeller airplane. All researchers searched for sea lions in the water at a speed of $190 \pm 26 \mathrm{~km} /$ $\mathrm{h}$ and an altitude of $232 \pm 42 \mathrm{~m}$. After surveying, the width of survey strip was roughly estimated by taking account of the following: (i) the distance between the eyes of the observer and the window of the airplane $(5 \mathrm{~cm})$; (ii) the distance from the lower edge of the window of the airplane to the eyes of the observer $(20 \mathrm{~cm})$; (iii) the angle of the sights $\left(14^{\circ}-\right.$ $60^{\circ}$ ); and (iv) the average altitude of the airplane. Based on these factors, the estimated width of survey strip was $802 \mathrm{~m}$, including $116 \mathrm{~m}$ of dead zone under the airplane. When sea lions were sighted in the survey strips, observers recorded the number of sea lions and location of the airplane. Photographs of sea lions in the survey strips were also taken with a single-lens reflex camera while circling above the sea lions. All aerial photos were taken when sea conditions had the Beaufort grade of lower than 4 .

Good quality photos were scanned by a film scanner, and the numbers of sea lions in the photographs were counted on a PC display. Only photos of sea lions collected on the one-way trips were 


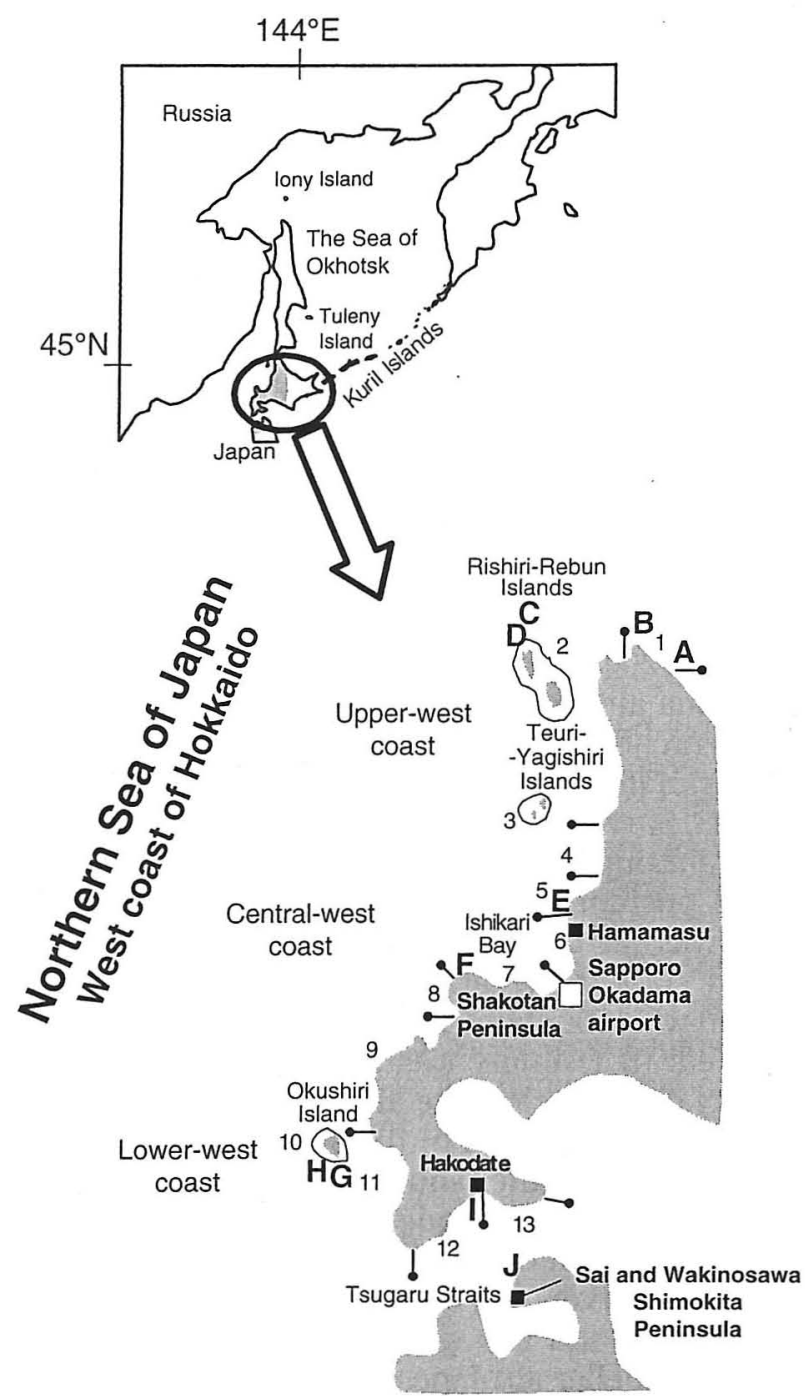

Fig. 1 Map of the northern Sea of Japan, along the west coast of Hokkaido and searched area. A, Onishibetsu Todo rocks; B, Benten Island; $\mathrm{C}$, Taneshima reef; $\mathrm{D}$, Hirashima reef; E, Cape Ofuyu; F, Cape Kamui; G, Murotsu Island; H, Muen Island; I, Cape Tachimachi; J, Ooyo Island. Substrip numbers: 1, WakkanaiOnishibetsu Todo rocks; 2, the Rishiri-Rebun Islands; 3, the Teuri-Yagishiri Islands; 4, Rumoi-Tomamae; 5, Cape Ofuyu-Rumoi; 6, Sapporo-Cape Ofuyu; 7, Sapporo-Cape Kamui; 8, Cape Kamui-Iwanai; 9, Iwanai-Cape Obana; 10, Okushiri Island; 11, Cape Obana-Cape Shirakami; 12, Cape Shirakami-Hakodate; 13, Hakodate-Cape Esan. Pins: Start and end of substrip.

used for analysis to avoid double counts. The survey strips searched were divided into 13 short strips: 1 . Wakkanai-Onishibetsu Todo rocks; 2. the RishiriRebun Islands; 3 . the Teuri-Yagishiri Islands; 4. Rumoi-Tomamae; 5. Cape Ofuyu-Rumoi; 6. Sapporo-Cape Ofuyu; 7. Sapporo-Cape Kamui; 8. Cape Kamui-Iwanai; 9. Iwanai-Cape Obana; 10. Okushiri Island; 11. Cape Obana-Cape Shirakami;
12. Cape Shirakami-Hakodate; and 13. HakodateCape Esan (Fig. 1). These substrips were then assigned to three different regions: (i) the upperwest coast of Hokkaido (substrips 1-5); (ii) the central-west coast of Hokkaido (substrips 6-8); and (iii) the lower-west coast of Hokkaido (substrips 9-13).

The number of sea lions sighted per length of searched substrip was used as encounter rates for representing the distribution of sea lions in coastal waters as we did not record the distance from the airplane to the sea lions in the water. The encounter rates were calculated only from the data obtained on 3 and 28 February, and March 1 2002; and 8 February, and 2 and 6 March 2003. The data on 28 February and 1 March 2002, and 2 and 6 March 2003 were combined, respectively. Data on 2 February 2003 could not be used for these calculations because we could observe only one substrip due to bad weather. Data in 2001 also could not be used for these calculations due to use of the older global positioning system. The numbers of sea lions in the water collected within $500 \mathrm{~m}$ of haulout rocks were also not used to calculate encounter rates. Due to technical problems with the global positioning system, the lengths of substrips at Iwanai-Cape Obana (9) and Okushiri Island (10) on 2 March 2003 were not recorded, and encounter rates in these substrips were therefore calculated using the lengths of the same substrips recorded on 8 February 2003.

Seven known haul-out sites and Cape Tachimachi were also observed from an airplane, together with the aerial survey of sea lions in the water (A to $\mathrm{G}$ and I in Fig. 1). Sea lions on the rocks and in the water within $500 \mathrm{~m}$ around haul-out sites were counted from photographs taken from the airplane. Data was only used for later analysis, when more than three haul-out sites were observed. The data on 1 and 2 March 2001; 28 February and 1 March 2002; and 2 and 6 March 2003 were combined, respectively. One disturbance due to our airplane was observed at Cape Ofuyu on 2 February 2003 , and one disturbance due to a shooting was observed at Cape Ofuyu on 8 February 2003. In both cases, sea lions rushed into the water from the haul-out rocks when our airplane or shooting boat was close to the haul-out rocks.

In order to collect additional information on sea lion distribution, records of sea lion sightings in the Tsugaru Strait were also collected from the Fisheries Promotion Division of the Agriculture, Forestry and Fisheries Department of Aomori Prefecture by email, and from one set-net fisherman in Hakodate City by direct oral communication in March 2002 and April 2003 (Fig. 1). The number of individuals, locations of sightings, and durations of stays were 
recorded. News articles related to sea lions were also collected from the To-o Nippo (To-o Nippo Press, Aomori) in May 2003.

\section{Observations at Cape Ofuyu and Cape Kamui}

The monthly changes were observed in number, sex and age class of wintering sea lions at Cape Ofuyu and Cape Kamui located at the mouth of Ishikari Bay from land, from a fishing boat and from an airplane from November 2002 to May 2003 (Fig. 1).

Observations from land were conducted for 20 days (total $29.0 \mathrm{~h}$ ) from 15 November 2002 to 5 May 2003 at Cape Kamui, and for 24 days (total $102.6 \mathrm{~h}$ ) from 15 December 2002 to 11 May 2003 at Cape Ofuyu. One or two researchers observed from a vantage point in the daytime with binoculars $(\times 8$ and $\times 10)$ and spotting scopes $(\times 20-\times 45)$. Observations lasted from $10 \mathrm{~min}$ to $9 \mathrm{~h} 30 \mathrm{~min}$ per day, depending on the weather conditions. Sea lions were counted both on the rocks and swimming in the water within approximately $500 \mathrm{~m}$ around the rocks. Each count was conducted every $30 \mathrm{~min}$ when observation was longer than $30 \mathrm{~min}$. When the counts differed between researchers, they were counted again in order to get a consistent number while checking the position of the sea lions on the rock. The maximum number of sea lions on each day was used for analysis because of differences in the length of observation, and to reduce the effects of disturbances during observation.

Sex and age class data were collected over 8 days at Cape Ofuyu and 3 days at Cape Kamui. The sex and age class of sea lions at the haul-out sites were classified by a single researcher at the haulout sites, as described by Porter. ${ }^{13}$ The categories included: (i) adult and subadult males which have the massive head; (ii) yearlings and pups which have significantly small body size; and (iii) medium-sized animals which included both females and young males. At Cape Ofuyu, sea lions both on the rocks and swimming around the rocks were classified; swimming animals that were difficult to classify were categorized as unknown. At Cape Kamui, only sea lions on the rocks were classified as the observation point was too far from the haul-out rock to classify the sex and age class of sea lions swimming in the water. Sea lions on the rocks that were difficult to classify were categorized as unknown. Sea lions marked as newborns in the rookeries in Russian waters were also observed at the haul-out sites. These marked animals of known age and sex were used as reference animals to identify the sex and age class of the other sea lions.

Sea lion observations were also conducted from a small fishing boat at Cape Ofuyu on 19 and 29
April 2003 during calm weather. Numbers were counted with binoculars at a distance of 100-200 m from the haul-out rocks to avoid disturbing the sea lions.

In order to collect additional information on sea lions at Cape Ofuyu and Cape Kamui, sighting records and photos of sea lions at the haul-out sites were also collected by direct questioning of three photographers living around Sapporo; one diving service and one youth hostel that provide sea lion watching tours in Shakotan Town, a gill-net fisherman in Hamamasu Town, and members of the Hamamasu fishery cooperative association from December 2002 to May 2003. Five sightings by interviews and five photos by photographers at Cape Kamui, and five sightings by interviews and one photo by a photographer at Cape Ofuyu were collected. In addition to sighting records, dates of sea lion shooting to control fishing damage were collected from fisherman due to the fact that shooting causes a disturbance at the haul-out sites.

Photos covering the entire haul-out sites were scanned and displayed on a computer, and sea lions were counted on the computer display by a single researcher. Five photos were taken on 23 December 2002, 3 and 11 January, and 4 and 23 February 2003 at Cape Kamui. Three of five photos (3 January, 4 and 23 February 2003) were used for counting sea lion numbers on the haul-out rock. Three of five photos (23 December 2002, and 3 and 11 January 2003) were also used for classifying sex and age class of sea lions on the haul-out rock. One photo taken on 2 December 2002 at Cape Ofuyu was used for counting sea lion numbers. Sex and age classification from photographs were conducted in a similar manner as the classification at the haul-out sites.

The numbers of sea lions collected from land, photo and aerial surveys were combined as the difference of counts depending on the different methods (airplane, boat, land observations) were thought to be smaller than changes in monthly numbers. The authors were able to observe the main areas of the haul-out sites where sea lions concentrated without blind zone regardless of the methods, although minor parts of haul-out sites have a blind zone in each survey method.

\section{RESULTS}

\section{Aerial survey and reports of sea lions in the northern Sea of Japan}

Observations of three sea lions on 3 February 2002, a total of 94 sea lions on 28 February and 1 March 2002, 56 sea lions on 8 February 2003, and a total of 
33 sea lions on 2 and 6 March 2003 between the Tsugaru Strait and the Rishiri-Rebun Islands were made (Table 1). Sea lions in coastal waters were observed around the Rishiri-Rebun Islands (2), the Teuri-Yagishiri Islands (3), Cape Ofuyu-Rumoi (5), Sapporo-Cape Kamui (7), Cape Kamui-Iwanai (8), Iwanai-Cape Obana (9), and Cape Obana-Cape Shirakami (11). The highest encounter rate of sea lions in 2002 was observed in the Rishri-Rebun Islands on $1 \mathrm{March}(0.406$ sea lions $/ \mathrm{km})$. In 2003, the highest encounter rate was observed in IwanaiCape Obana on 8 February $(0.421$ sea lions $/ \mathrm{km})$, however, it was low on 2 March (0.033 sea lions/ $\mathrm{km})$. The highest encounter rate in March of 2003 was in the Rishiri-Rebun Islands on 6 March, $(0.165$ sea lions $/ \mathrm{km}$ ).

Sea lions at the haul-out sites were observed at Taneshima reef by Rebun Island in 2002, Cape Ofuyu and Cape Kamui in the all three searched years, and Murotsu Island by Okushiri Island in 2003. In addition, one sea lion was observed at Muen Island, by Okushiri Island, that was not expected to be a haul-out in 2001. Higher numbers of sea lions were observed at Cape Kamui and Cape Ofuyu in all three searched years than at the Taneshima reef and at the other historical haul-out sites on the upper-west coast of Hokkaido investigated in this survey (Table 2).

Interviews with fisherman in Hakodate city confirmed that seven sea lions were observed along the coast of Hakodate in mid-March 2002, and four to nine sea lions stayed in the coast of Hakodate and hauled out on Cape Tachimachi from February to April 2003. Fisherman assumed that these animals were Steller sea lions because fisherman often saw the northern fur seal Callorhinus ursinus in the Tsugaru Strait and could distinguish Steller sea lions from fur seals by the difference in body size and color. Ten to 20 sea lions stayed on the coast of Sai and Wakinosawa (west coast of the Shimokita Peninsula) from February to May 2003. To-o Nippo also reported a sighting of sea lions on 20 May 2003 , with a photo of a sea lion hauling out on Ooyo Island (Fig. 1).

\section{Observations at Cape Ofuyu and Cape Kamui}

Sea lions were first sighted at Cape Ofuyu on 12 November by a local fisherman, and at Cape Kamui on 14 December by this study. At Cape Kamui, 0 to 188 sea lions were observed (average: 36.2 animals) during December to May; more than 50 animals (average: 76.6 animals) were observed between 3 January and 8 February, after which the number of sea lions decreased. At Cape Ofuyu, 9-121 animals (average: 57.0 animals) were observed during

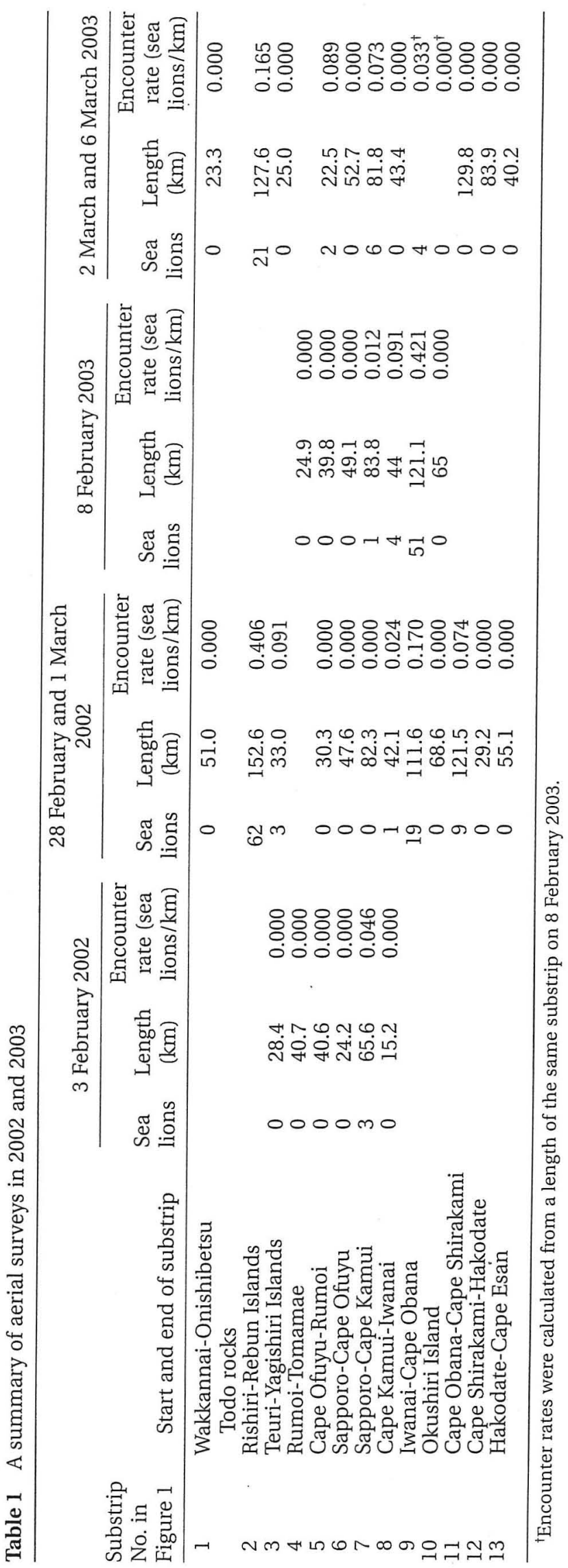


Table 2 Numbers of sea lions observed at/around haul-out sites by present study's aerial survey and reported by Yamanaka et $a l^{4}$

\begin{tabular}{|c|c|c|c|c|c|c|}
\hline \multirow[b]{2}{*}{ Haul out sites } & \multirow{2}{*}{$\begin{array}{c}\text { Location of } \\
\text { haul-out } \\
\text { sites }^{\dagger}\end{array}$} & \multirow{2}{*}{$\begin{array}{c}2001 \\
1 \text { and } \\
2 \text { March }\end{array}$} & \multirow{2}{*}{$\begin{array}{c}2002 \\
28 \text { February } \\
\text { and } 1 \text { March }\end{array}$} & \multicolumn{2}{|c|}{2003} & \multirow{2}{*}{$\begin{array}{l}\text { 1980s } \\
\text { Yamanaka } \\
\text { et al. }{ }^{4}\end{array}$} \\
\hline & & & & 8 February & $\begin{array}{c}2 \text { and } \\
6 \text { March }\end{array}$ & \\
\hline Onishibetsu Todo rocks & (A) & & 0 & & & 150 \\
\hline Benten Island & (B) & & 0 & & 0 & $50-60$ \\
\hline Taneshima reef & (C) & & $8^{\ddagger}$ & & 0 & Several \\
\hline Hirashima reef & (D) & & 0 & & 0 & $10-20$ \\
\hline Cape Ofuyu & (E) & 215 & 14 & 2 & 81 & $1-2$ \\
\hline Cape Kamui & (F) & 82 & 17 & 70 & 14 & \\
\hline Murotsu Island & (G) & 0 & 0 & 4 & 5 & 0 \\
\hline Muen Island & $(\mathrm{H})$ & 1 & 0 & 0 & 0 & \\
\hline Cape Tachimachi & (I) & & 0 & & 0 & \\
\hline
\end{tabular}

${ }^{\dagger}$ Locations of haul-out sites were shown in Figure 1.

‡Sea lions were observed in the water within $500 \mathrm{~m}$ of the haul-out rocks.

Table 3 Sightings of sea lions at the haul-out sites

\begin{tabular}{|c|c|c|c|c|c|}
\hline \multicolumn{3}{|c|}{ Cape Ofuyu } & \multicolumn{3}{|c|}{ Cape Kamui } \\
\hline Date & No. animals & Observer (sighting from) & Date & No. animals & Observer (sighting from) \\
\hline 12 November 2002 & 120 & Fisherman (boat) & $1 \operatorname{Jan} 2003$ & 93 & Youth Hostel staff (land) \\
\hline 1 January 2003 & 96 & Photographer (land) & 18 Feb 2003 & 12 & Photographer (land) \\
\hline 20 January 2003 & 80 & Photographer (kayak) & 21 Feb 2003 & 6 & Diving service (land) \\
\hline 5 May 2003 & 25 & Photographer (boat) & 25 Feb 2003 & 0 & Fisherman (boat) \\
\hline 25 May 2003 & 0 & Fisherman (boat) & 2 Apr 2003 & 0 & Photographer \\
\hline
\end{tabular}

Land, the same position as present study's observation point.

December to May, and numbers decreased in early May (Fig. 2). Collected sightings showed a similar monthly trend and were within the range of the counts, with the exception of a sighting on 12 November. A high number of sea lions at Cape Ofuyu were sighted in January, and then number became low in May, whereas sightings at Cape Kamui confirmed that the number of sea lions was low in February (Table 3).

Decreases in the number of sea lions at Cape Ofuyu were also observed after shooting disturbances from 16 to 23 February (Fig. 2). A smellharassment device, which spreads the smell of cresol, was set to remove sea lions from Cape Ofuyu by the Fisheries Science of Hokkaido University on a major haul-out rock of Cape Ofuyu on 3 February, after which the number of sea lions decreased.

Sex and age class data showed that the population at Cape Ofuyu from 12 January to 11 May consisted of 7-91 (average: 55.4) adult and subadult males, 0-38 (average: 13.6) middle-sized animals, 0-4 (average: 2) yearlings and pups, and 0-9 (average: 2.6) animals of unknown sex and age class. At Cape Kamui, the numbers of each group were 29-
60 (average: 43) adult and subadult males, 3-43 (average: 18.2) middle-sized animals, 0-2 (average 0.5 ) yearlings and pups, and $0-1$ (average: 0.2 ) animals of unknown sex and age class from 23 December to 7 February (Fig. 3). The proportions of each group calculated from those average number of sea lions in each group were $75.2 \%$ adult and subadult males, $18.5 \%$ middle-sized animals, $2.7 \%$ yearlings and pups, and $3.6 \%$ unknown at Cape Ofuyu, and $69.5 \%$ adult and subadult males, $29.4 \%$ middlesized animals, $0.8 \%$ yearlings and pups, and $0.3 \%$ unknown at Cape Kamui.

At Cape Ofuyu, the number of adult and subadult males peaked in February and March, decreased in April, and then remained unchanged throughout April, whereas middle-sized animals decreased gradually from January to April (Fig. 3). At Cape Kamui, the numbers of adult and subadult males increased from late December, remained stable throughout January, and decreased in February (Fig. 3). Middle-sized animals also showed similar changes as adult and subadult males. The numbers of yearlings and pups were small at both haul-out sites. Comparing the monthly numbers of adult and subadult males with middle-sized 


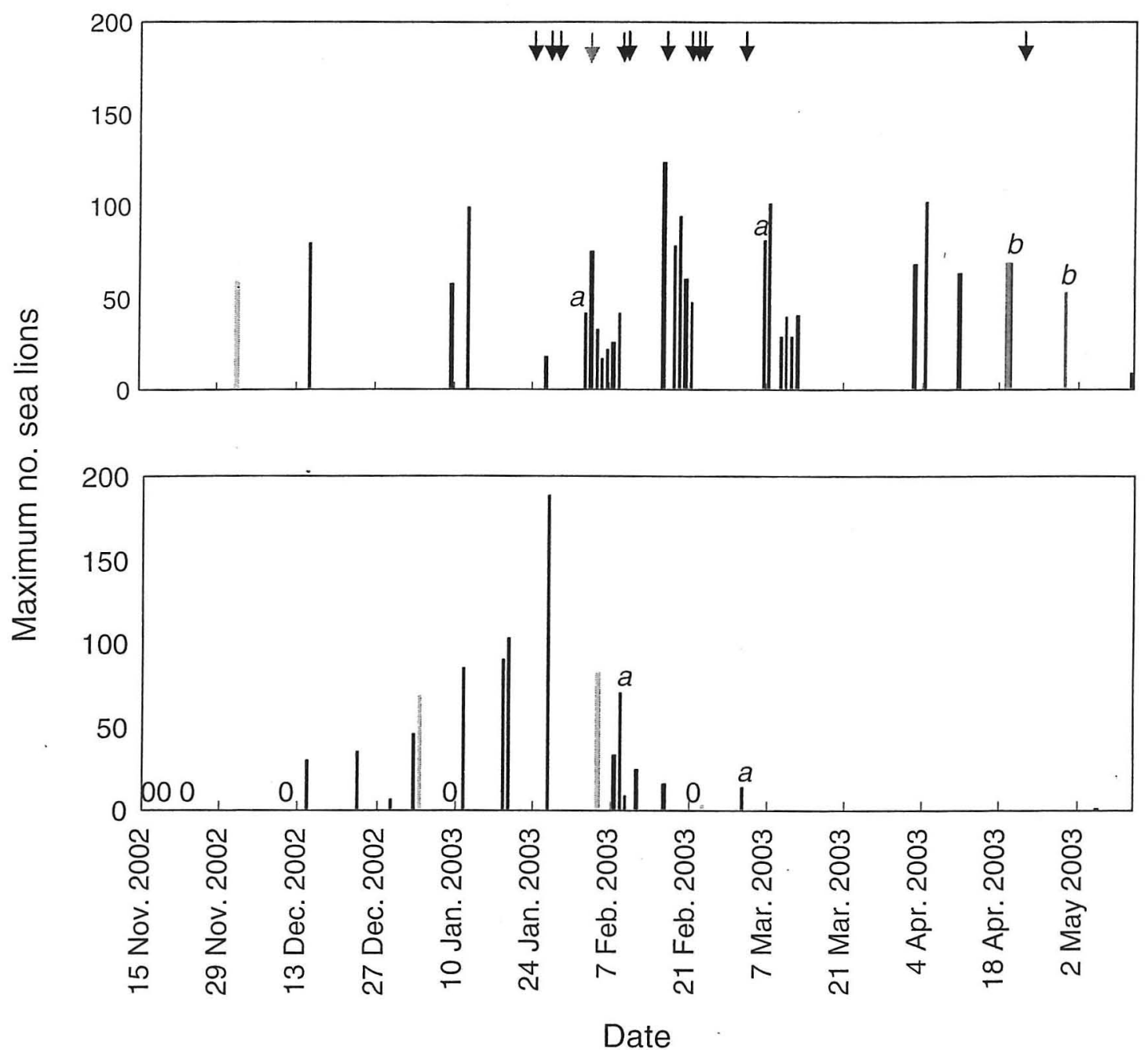

Fig. 2 Maximum numbers of sea lions counted at Cape Ofuyu (upper) and Cape Kamui (lower). Black column: Numbers of sea lions collected by observation from land. Grey column: numbers counted from photographs. Columns with $a$ : numbers of sea lions collected from an airplane. Columns with $b$ : numbers of sea lions collected by observation from a fishing boat. Blank, no data; 0, no sea lion observed at Cape Kamui; black arrows, sea lion disturbance due to shooting at Cape Ofuyu; grey arrows, set of smell harassment system.

animals at both haul-out sites, the numbers of adult and subadult males seemed to be more stable through the winter than the numbers of middlesized animals which changed month to month.

\section{DISCUSSION}

\section{Changes in the historical distributional of wintering sea lions}

Aerial surveys suggested that the distribution of sea lions in coastal waters was not uniform in the northern Sea of Japan, along the west coast of Hokkaido, and that sea lions gathered mainly between Iwanai and Cape Obana in early February and around the Rishiri-Rebun Islands in early March. In addition, Cape Ofuyu and Cape Kamui appear to be important haul-out sites for sea lions in the northern Sea of Japan, along the west coast of Hokkaido, as higher numbers of sea lions were observed at these haul-out sites than that at the other sites.

Studies in the 1980s observed few sea lions on Cape Ofuyu and the Shakotan peninsula in the central-west coast of Hokkaido during winter. Sea lions were also not reported in the Tsugaru Strait in the 1980s. ${ }^{4}$ These earlier studies reported a total of 210-230 sea lions on the Onishibetsu Todo rocks, Benten Island and the Rishiri-Rebun Islands in the 

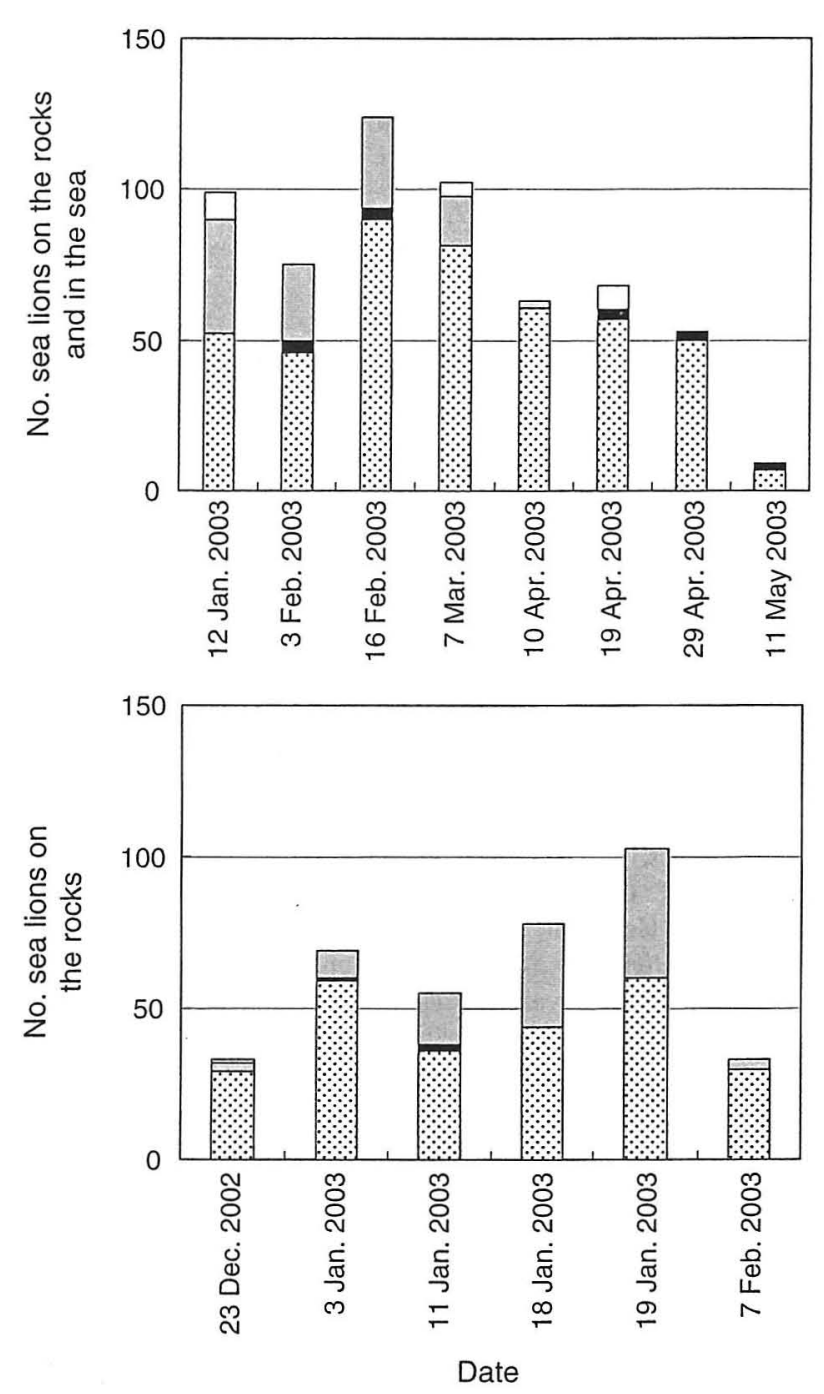

Fig. 3 Numbers of sea lions classified into each sex and age class category at Cape Ofuyu (upper) and Cape Kamui (lower). Dotted area, adult and subadult males; black area, pups and yearlings; grey area, medium-sized animals of unknown sex; white area, unidentified animals.

upper-coast of Hokkaido during 1980s (Table 2). ${ }^{4}$ Compared with the results presented in this study, these figures indicate that sea lions have changed their main haul-out sites and expanded their wintering area from the upper-west coast of Hokkaido to the central-west and lower-west coast of Hokkaido. This expansion is assumed to have occurred since the 1990s because sightings of sea lions in the west coast of Hokkaido started to increase in the early 1990s. ${ }^{7}$

The distribution of sea lions and their choice of haul-out sites are reported to be influenced by the availability of dietary fish. ${ }^{9,10}$ In the Sea of Okhotsk, walleye pollock Theragra chalcogramma decreased from 1988 to $1999 .{ }^{14}$ However, the fishery catch of arabesque greenling Pleurogrammus azonus increased in the northern Sea of Japan along the west coast of Hokkaido during the 1990s. ${ }^{15}$ Sea lions may have changed their diet from walleye pollock to more available arabesque greenling during this decade. Such changes of diet fish might have influenced the southward expansion of sea lions distribution and the development of Cape Kamui and Cape Ofuyu as the major haul-out sites in the northern Sea of Japan along the central-west coast of Hokkaido in a last decade. Further distributional study of sea lions and their diet fish in the northern Sea of Japan along the west coast of Hokkaido is needed.

\section{Comparisons with the temporal changes in distribution, sex and age class of sea lions in the central-west coast of Hokkaido in the 1980s}

Sea lions were present at Cape Ofuyu from November 2002 to May 2003, and at Cape Kamui from December 2002 to May 2003. The numbers of sea lions at Cape Kamui had peaked in January 2003, whereas those at Cape Ofuyu were relatively stable during December 2002 to May 2003. Therefore, sea lions stay in the central-west coast of Hokkaido between December and May, and the peak season of sea lion abundance staying in this area is January. Unlike this present study, sea lions were sighted from January to April around the Shakotan Peninsula in the central-west coast of Hokkaido in the 1980s. ${ }^{4}$ Sea lions in this present study arrived in the central-west coast of Hokkaido earlier and stayed longer compared to that reported in the 1980s. The results of this present study show that the recent temporal changes in sea lion distributions in the central-west coast of Hokkaido are different from those of the 1980s.

The results of sex and age classifications showed that approximately $70 \%$ of the populations at both haul-out sites were adult and subadult males. A few numbers of pups and yearlings were also observed at both haul-outs sites. Isono and Wada reported that captured sea lions in the winter of the 1990s were mostly composed of adult males around the Shakotan Peninsula based on the microscopic canine tooth analysis. ${ }^{2}$ Observations made in this present study, at both haul-out sites, are consistent with their report. The group of sea lions has consisted mainly of adult and subadult males in the central-west coast of Hokkaido since the 1990s. In the 1980s, Yamanaka et al. suggested that sea lions consisted mainly of young males in the central-west coast of Hokkaido in winter, 
based on the captures and sighting records. ${ }^{4}$ However, this suggestion was based on a single information source. Results of the recent study show that male sea lions of older age class stay in the central-west coast of Hokkaido compared to that reported in the 1980s.

In addition, the monthly counts of sea lions in each sex and age group indicate that subadult and adult males tend to remain at both haul-out sites longer than middle-sized animals. This is the first report showing that the different sex and age class of sea lions stay in the central-west coast of Hokkaido for the period of different length. In the Kuril Islands, the female gives birth to one pup between mid May and mid July of every year, ${ }^{16}$ and breeding adult males must come back to the rookery earlier than females to establish territory. ${ }^{17}$ It is speculated that non-breeding sea lions stay in the central-west coast of Hokkaido until May, although breeding sea lions leave the central-west coast of Hokkaido in March.

\section{CONCLUSION}

Winter distribution of sea lions has expanded from the upper-west coast of Hokkaido to the lowerwest coast of Hokkaido since the 1990s. This is based on the fact that sea lions in coastal waters were often observed in the central-west and the lower-west coast of Hokkaido in the winters of 2001-2003, and that the location of major haul-out sites have changed from the upper-west coast of Hokkaido to the central-west coast of Hokkaido since the 1990s.

Sea lion groups, composed of mainly adult and subadult males, were observed in the central-west coast of Hokkaido from November of 2002 to May 2003. This indicates that in addition to the difference in location of major haul-out sites, sea lions are also arriving earlier in the central-west coast of Hokkaido and staying longer than those reported in the 1980s.

\section{ACKNOWLEDGMENTS}

The authors are grateful to Naoki Iwai, Toshikazu Sato, Yoshimichi Furukawa, Takafumi Hino, Mayumi Ueno, Yasuko Kamezawa, Hikaru Koide, Maya Uranishi, Takuya Ikawa, Ayako W. Mizuno, Seiichi Hamada, Mitsuo Kagiya, Hisato Fujita, Yoshifusa Suzuki, the Shakotan Peninsula Restaurant, Shakotan Town, Hamamasu Town, the Fisheries Promotion Division of the Agriculture, Forestry and Fisheries Department of Aomori Prefecture and the Hokkaido Aviation. Also, the authors would like to give special thanks to Robin Rigby and Derek Goto. This study was supported by the Fisheries Agency of Japan.

\section{REFERENCES}

1. Loughlin TR, Perez MA, Merrick RL. Eumetopias jubatus. Mamm. Spec. 1987; 283: 1-7.

2. Isono T, Wada K. Migration of Steller sea lions Eumetopias jubatus around Hokkaido Island, Japan. In: Ohtaishi N, Wada K (eds). Migratory Ecology and Conservation of Steller Sea Lions. Tokai University Press, Tokyo. 1999; 230247.

3. Loughlin TR, Perlov AS, Vladimirov VA. Range-wide survey and estimation of total number of Steller sea lions in 1989. Mar. Mamm. Sci. 1992; 8: 220-239.

4. Yamanaka M, Ohtaishi N, Itoo T. Migration of Steller sea lion and their damage to fisheries along the Hokkaido coast, Japan. In: Wada K, Itoo T, Niizuma A, Hayama S, Suzuki M (eds). Ecology and Conservation of Kuril Seal. Tokai University Press, Tokyo. 1986; 274-295.

5. Wada $K$, Goto $Y$, Isono T. Steller sea lion conservation around Hokkaido Island, Japan. In: Ohtaishi N, Wada K (eds). Migratory Ecology and Conservation of Steller Sea Lions. Tokai University Press, Tokyo. 1999; 250-313.

6. Ishinazaka T. Seals and Steller sea lions off the Shiretoko peninsula. In: Shari Shiretoko Museum (ed.). Shiretoko Library 2: mammals in Shiretoko I. Hokkaido Shimbun Press, Sapporo. 2000; 164-205 (in Japanese).

7. Isono T. 1.1 Steller sea lion (2) fishery damage caused by sea lions and measure against the damages. In: Kobayasi $M$, Isono T, Hattori K (eds). Management of Marine Mammals Along the Coast of Hokkaido, Japan. The Marine Wildlife Center of Japan, Sapporo. 2004; 5-18 (in Japanese).

8. Goto Y. Feeding ecology of Steller sea lions. In: Ohtaishi N, Wada K (eds). Migratory Ecology and Conservation of Steller Sea Lions. Tokai University Press, Tokyo. 1999; 14-58.

9. Womble JN, Willson MF, Sigler MF, Kelly BP, VanBlaricom GR. Distribution of Steller sea lions Eumetopias jubatus in relation to spring-spawning fish in SE Alaska. Mar. Ecol. Prog. Ser. 2005; 294: 271-282.

10. Sigler MF, Womble JN, Vollenweider JJ. Availability to Steller sea lions (Eumetopias jubatus) of a seasonal prey resource: a prespawning aggregation of eulachon (Thaleichthys pacificus). Can. J. Fish. Aquat. Sci. 2004; 61: 1475-1484.

11. Wada A. Northern fur seal and sea otter, (1) ecology and management problem of northern fur seal. In: Kobayashi $\mathrm{M}$, Isono $\mathrm{T}$, Hattori $\mathrm{K}$ (eds). Management of Marine Mammals Along the Coast of Hokkaido, Japan. The Marine Wildlife Center of Japan, Sapporo. 2004; 37-40 (in Japanese).

12. Le Boeuf BJ, Crocker DE, Costa DP, Blackwell SB, Webb PM, Houser DS. Foraging ecology of northern elephant seals. Ecol. Monogr. 2000; 70: 353-382.

13. Porter BT. Winter ecology of Steller sea lions (Eumetopias jubatus) in Alaska. MSc Thesis. University of British Columbia, Vancouver B.C. 1997.

14. Radchenko VI. Tangible outline of the whole elephant (results of ecosystem studies of biological resources in the far-eastern seas in 1990s). PICES Press 2001; 9: 20-24. 
15. Ueda Y, Maeda K, Shimada H, Takami T. Fisheries and Aquatic Life in Hokkaido. The Hokkaido Shimbun Press, Sapporo. 2003.

16. Belkin AN. Summer distribution, resources, hunting prospects and some biological features of sea lions (Eumetopias jubatus, Schreb., 1776), of the Kuril Islands. Proceeding of the Pacific Scientific Research Institute of Fisheries and Oceanography. 1966; 58: 69-95 (in Russian).

17. Gentry RL. Social behavior of the Steller sea lion. PhD Thesis. University of California, Santa Cruz. 1970. 